\title{
Eigenstructure Conditions for Loop Transfer Recovery
}

\section{Søgaard-Andersen, Per}

\section{Published in:}

American Control Conference

Publication date:

1988

\section{Document Version}

Publisher's PDF, also known as Version of record

Link back to DTU Orbit

Citation (APA):

Søgaard-Andersen, P. (1988). Eigenstructure Conditions for Loop Transfer Recovery. In American Control Conference (pp. 1254-1259). IEEE.

\section{General rights}

Copyright and moral rights for the publications made accessible in the public portal are retained by the authors and/or other copyright owners and it is a condition of accessing publications that users recognise and abide by the legal requirements associated with these rights.

- Users may download and print one copy of any publication from the public portal for the purpose of private study or research.

- You may not further distribute the material or use it for any profit-making activity or commercial gain

- You may freely distribute the URL identifying the publication in the public portal

If you believe that this document breaches copyright please contact us providing details, and we will remove access to the work immediately and investigate your claim. 


\title{
EIGEUSTRUCTLRE CONDITIONS FOR LOOP TRASFER RECOVERY
}

\author{
Per Sygaard-Aodersen
}

Control Engineering Institute, Technical Oniversity of Dennark

Bldg. 424 - DK-2800 Lyngby, Dermark

\begin{abstract}
Conditions for loop transfer recovery based on eigenstructure assignent are derived. These conditions inply constraints on the eigenvalues and certain paraneter vectors of the controller. Three cases energe - depending on the geonetric stucture of the plant. For all cases explicit design rules are derived. The eigenstructure-LTR approach provides - beyond insight into nechanisss of LTR - improved flexibility in selecting the controller gains and faster recovery convergence as conpared with the IQG-based LTR method. These issues are illustrated in an exanple.
\end{abstract}

\section{Introduction.}

In the last decade a number of new tools for control systen design with robustness specifications have energed. One of the nost useful has been the Linear-Quadratic-Gaussian procedure with Loop Transfer Recovery (LOG/LTR). In this procedure a target feedback loop (fullstate or observer) which reflects the robustness sperifications is recovered with some suitable asymptotic design [s2].

In this paper the focus is on the second step of this procedure - the recovery step. Based on an eigenstructure interpretation of the recovery principle an alternative to the LQG-based LTR method is presented.

The notivation for working with this alternative method is that the eigenstructure approach provides the designer with more flexibility in selecting gains of ninimal anplitude - while still satisfying the specifications - and faster convergence of the recovery proces (which also produces swaller gains), beyond the new insight into the mechanisus of recovery that it provides. Recently Razerooni and Boupt [R1] has derived sone results concerning eigenstructurebased LTR. However, as it is pointed out in [55], these results only guarantee LTR in very special cases. In [S5] some inproved results were outlined, but here certain assumptions on the geonetric structure on the plant vere imposed.

In this paper no such assunptions are inposed, and a more general approach to LTR based on eigenstructure assignment is presented. The new results are based on the analysis of the eigenstructure of highgain feedback systens presented in [54]. The present paper does not discuss the theoretical background. Such a perspective can be found in $[54,56]$.
The paper is organized as follows. In $\$ 2$ the robustness concepts underlying the LIRapproach are briefly discussed. In 3 the eigenstructure equations are introduced, followed in s 4 by the outline of the eigenstructure-LTR results. In 5 sone remarks on the usefulness of this design-concept are given, and in 6,7 sone examples and concluding remarks are provided.

\section{The significance of 1000 transfer recoyery.}

The loop transfer recovery concept is related to control system robustness via the recently developed singular value-based loopshaping paradign. In this setting the robustness constraints are formulated as frequency-dependent bounds that the maximu singular value of the sensitivity and complenentary sensivity finctions nust satisfy:

$$
\begin{aligned}
& \sigma_{1}[5(j w)]<g(w) \\
& \sigma_{1}[T(j w)]<l(w)
\end{aligned}
$$

The first condition imposes certain performance constraints on the control loop, and the second condition inply certain stability robustness specifications.

often these constraints can be reformulated as specifications on the singular values of the loop transfer natrix. A nore profound statement of these issues can be found in $[D 2, M 1]$.

One approach to the design under such loopshape specifications is nodel-based conpensation. In this approach the specifications are satisfied via sone target design (full-state or observer design). This design are then recovered to any prescribed degree of accuracy with a loop transfer recovery design - provided that the plant is ninimun-phase $[D 2, A 1, s 2]$.

With this procedure robustness contraints inposed on either the plant input or output can be satisfied.

Specific nethods of target feedback design are discussed in refs. $[A 1, B 1,53,54]$.

In this paper it will frow hereon be assumed that the target design has been perforned as a full-state design (i.e. robustness specifications reflected to the plant input node), and the recovery design is therefore an observer-design. 


\section{Eirenstructure desion of observers.}

The systens considered are the usual ninimal state-space systens $S(A, B, C)$ with $n$ states and inputs/outputs (i.e. a square systen). Further it will be assuned that the plant is ninimu-phase. The transfer natrix of the plant will be denoted P(s).

The (already assigned) full state gain is called $X$ and the observer gain (to be assigned) is denoted $F$. The total wodel-based compensator is called $\mathrm{C}(\mathrm{s})$.

The basic idea in eigenspace design of observers is to apply the freedon beyond poleplacenent to place the left observer eigenvectors. This is often reasonable since many observer design issues are readily formulated in terms of the left eigenvectors (e.g. suppression of initial estimation errors, filter gain mininization).

Here, it is the purpose to define the subspaces which the left eigeavectors nust belong to, and the pole-locations that will guarantee recovery of the full-state loop transfer.

First, hoyever, consider the left observer eigenvectors $w_{i}$ of the observer-100p A-FC:

$$
v_{i}^{T} \quad(2-\mathrm{FC})_{i}={ }_{i}^{I_{\lambda}} * i=1, \ldots, n(3-1)
$$

A. denotes the $n$ eigenvalues of A-FC. After soine reordering eq. $(3-1)$ becones:

$$
\begin{aligned}
& {\left[\lambda_{i} I-\lambda^{T},-c^{T}\right]\left[\begin{array}{c}
w_{i} \\
-I^{I} w_{i}
\end{array}\right]=0 \quad i=1, \ldots, n} \\
& {\left[\lambda_{i} I-\lambda^{T},-c^{T}\right]\left[\begin{array}{c}
w_{i} \\
z_{i}
\end{array}\right]=0} \\
& {\left[\begin{array}{c}
w_{i} \\
z_{i}
\end{array}\right] \in \operatorname{Rer}\left[\lambda_{i} I-\lambda^{I},-c^{I}\right]}
\end{aligned}
$$

In the following it is assuned that $(C, A)$ is an observable pair.

This inplies that any eigenvalues $\lambda$, can be selected. If $\lambda_{i}$ does not belong to the spectrum of $A$, eq. $(3-2)^{1}$ can be sinplified to:

$$
u_{i}{ }^{T}=z_{i}{ }^{T} \operatorname{c\leftrightarrow }\left(\lambda_{i}\right), \phi(s)=(s I-\lambda)^{-1}
$$

This equation shows that wir nust belong to a n-dinensional subspace defined by $\lambda_{i}$. The specific eigenvectors are deternined by the paraneter vectors $z$, consequently eigenvector-selection is pquivalent to selecting appropriate vectors $z_{i}$.

Corresponding to $n$ specific selections of eigenvectors are a filter gain F. From eq. (3-2) it is found that:

$$
\left[\begin{array}{l}
w_{1}{ }^{T} \\
\vdots \\
w_{n}{ }^{T}
\end{array}\right]=\left[\begin{array}{c}
-z_{1}{ }^{T} \\
\vdots \\
-z_{n}{ }^{T}
\end{array}\right]
$$

$$
\begin{aligned}
& w=-2 \\
& F=-v^{-1} 2
\end{aligned}
$$

clearly a gain F can only be found if the left eigenvector natrix $\boldsymbol{v}$ is nonsingular.

Hotice that $F$ is a matrix of real elements if the eigenvalues and paranetervectors are in conplex-conjugate pairs.

\section{ITR with eigenspace techniques}

In this section the specific choices of $z$ T and $\lambda_{\text {. }}$ wich facilitates loop transfer recovely are found.

The derivation is based on the following result fron ref. (10).

For a vininal, square and ninimu-phase systen a full state $200 p$ transfer - with the input node as loop breaking point - can be recovered asyutotically if the observer gain selected so that:

i) the observer-poles are stable

ii) $\frac{E(q)}{q}+B,|\alpha| \neq 0, q \rightarrow \cdots$

Here $g$ is some paraneter which $A_{i}$ and $z_{j}{ }^{T}$ are functions of. First the eigenvalue-belection is considered. In [ $[1]$ it was found that $p$ eigenvalues approach the zeros of $S(A, B, C)$. The renaining $n-p$ eigenvalues mst approach infinity. In the LoG-setting the fast eigenvalues group into Butterworth patterns [S1].

Bence the following eigenvalue-selection is adequate:

i) p eigenvalues $\lambda_{i}$ approach the zeros of $S(A, B, C)$.

ii) n-p eigenvalues group into a fast Butterworth patterns.

Let the $p$ zeros be denoted $z$. The fast poles wust be grouped into a patterns. Let the radii of the $j$ 'th pattern be $\lambda_{\text {r }}$ and let the order of the $j$ 'th pattern be $l_{j}$.

The ITR-proble thereford concerns the selection of $\lambda_{r j}, 1_{j}$ and the vectors $z_{i}{ }^{I}(j=1, \ldots, n)$.

The condition $F / q \rightarrow B a$ restricts the allowable $z{ }^{2}$. If the filter gain $F$ og eq. $(3-4)$ is inserted in this condition:

$$
\begin{aligned}
& -\frac{v^{-1} q}{q}+B \alpha, q \rightarrow \\
& -\frac{z}{q}+W B \alpha \\
& -\frac{z_{i}{ }^{T}}{q}+z_{i}{ }^{T} C+\left(\lambda_{i}\right) B \alpha \quad i=1, \ldots, n
\end{aligned}
$$

The last equation inplies that any $z_{i}{ }^{T}$ wust satisfy the linit. 
If $\lambda(q)$ is approaching a zero $z$ the right hand side of eq. (4-1) can be finite whereas the left hand side converges to zero, consequently $z_{i}$ must satisfy:

$$
\begin{aligned}
& z_{i}{ }^{T} C \psi\left(z_{\circ i}\right) B a \rightarrow 0 \quad i=1, \ldots, p \\
& z_{i} \in \operatorname{Rer}\left[\left(C \downarrow\left(z_{O i}\right) B\right)^{T}\right]
\end{aligned}
$$

This value of $z^{T}$ is denoted a left zerodirection of $S(A, B, C)[R 1]$. Generically the rank of $C \uparrow\left(z, B\right.$ is $a-1$, so $z_{i}$ nust belong to $a 1-$ dimensiotal subspace. Hetce the corresponding left eigenvector $w_{j}$ is uniquely determined. The selection of the paraneter vectors $z_{i}{ }^{T}$ and $\lambda_{r j}$ and 1 associated with fast poles can de divided into $j$ three distinct problems. Details of the derivation are found in [S4]. The three cases differs in the geonetric properties of the Markov paraneters of $S(A, B, C)$.

Oniform rank systens - Let the Markov parameters of $S(A, B, C)$ be $P_{i}=C A^{1-1} B$, and:

$$
\begin{aligned}
& p_{i}=0, i=1, \ldots, k-1 \\
& \left|P_{k}\right| \neq 0
\end{aligned}
$$

Then ITR is obtained if:

$$
1_{1}=\ldots=1_{m}=k
$$

The radii $\lambda$, are free to select, and further the parametef ${ }^{j}$ vectors $z_{i}$ associated with each Butterworth pattern are equal (except for a scaling), but free to select.

If the uniform-rank condition is not satisfied the infinite zeros will be of different order. The radii $\lambda_{\text {, }}$ are still free parameters, but the vectors $z_{i} T$ ate constrained.

Two tases energe: (Non-uniform-rank - NOR)

Sinple-structure (SS) NOR - This special class of NUR are defined by:

$$
\begin{aligned}
& N_{L}\left(P_{1}\right) \in \ldots \in N_{L}\left(P_{1}\right) \in \ldots \in N_{L}\left(P_{1}\right) \quad(4-3) \\
& P_{i}=C A^{i-1} B \\
& \operatorname{dim} N_{L}\left(P_{j}\right)=\operatorname{dim} N_{L}\left(P_{j-1}\right)-t_{j}, j=1, \ldots, I_{I}
\end{aligned}
$$

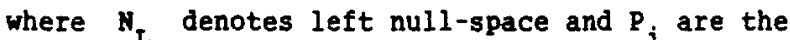
Markov páraneters. The integers $l_{j}$ are the orders of the infinite zeros defined by the projected Markov paraneters of $S(A, B, C)$ (these paraneters are defined in $[\pi 2]) . t_{j}$ is number of infinit zeros of order $l_{j}$. The paraneter vectors $z_{j}$ associated with an infinite zero of order $1_{j}$ afe given by:

$$
z_{i}{ }^{T} \in{ }_{k=1}^{1}{ }^{-1} N_{L}\left(P_{k}\right)=s_{1 j}, z_{i}{ }^{T} P_{1_{j}} \neq 0 \quad(4-4)
$$

$A 11$ vectors $z^{\mathrm{T}}$ of a Butterworth pattern are equal (except for acaling).

Non-sinple structure (NSS) NUR - Any system not characterized by any of the first two classes fall into this group.

The parameter vectors $z_{i}^{T}$ are defined by:

$$
\begin{array}{ll}
z_{i}^{T}=\sum_{j=0}^{l_{i}^{-2} \frac{x_{j}}{\lambda_{i}^{j}}} & 1_{i} \geqslant 2 \\
z_{i}{ }^{T} C B \neq 0 & 1_{i}=1
\end{array}
$$

tion.

The integers 1 have the usual interpretaThe vectors $x_{i}{ }^{i}$ are defined by the left nullspace of the Toeplitz matrix:

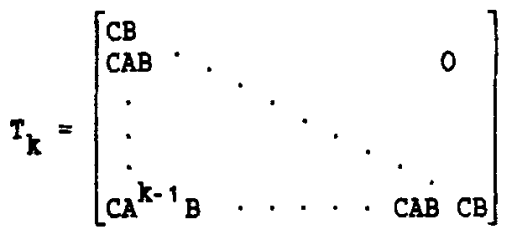

$$
\begin{aligned}
& {\left[x_{1}{ }^{2} \cdot \cdots x_{0}\right] \in N_{L}\left(T_{x}\right)}
\end{aligned}
$$

For each Butterworth patterp the term $x_{0}$ in eq. $(4-5,4-6)$ is equal for all $z$ (except for a scailing), hence $z_{i}$ can be written as:

$$
z_{i}^{T}=x_{0}+z_{i q}^{T}
$$

where $z_{i g}$ is a vector-function in $q$ and $\lambda_{i}$. As $q \rightarrow \infty, q_{i}$ will approach $x_{0}$.

In all three cases it is further required that rank $(Z)=m$, and that the resulting eigenvector-natrix is nonsingular. None of these restrictions are serious, however.

Further note that the conditions here are sufficient conditions (for details on this issue see the Appendix). The scaling mentioned in all 3 cases can be complex, subject only to the complex-conjugate requirements mentioned in 3 .

NSS non-unifor rank systems are associated with systens $S(A, B, C)$ with a geonetrically less transparent left null-space structure of the Markov parameters. However, practical experience indicates that many systens belong to one of the first two categories. Systens with less than 3 inputs and systens with infinite zeros of orders strictly less than 3 are always of simplestructure or of unifor rank. For all 3 cases the parameter vectors $z_{j}{ }^{\mathrm{T}}$ are deternined by Markov parameters of $S(A, B, C)$. The actual deternination af allowable $z$ vectors is a straightforward exercise once the Markov parameters of $S(A, B, C)$ are known. Once allowable $z_{i}{ }^{\mathrm{T}}$ vectors are found the corresponding left eigenvector subspaces can be found. 
In all three cases the vectors $z^{T}$ are not uniquely deternined. Hence sone extra ffeedon in selecting left eigenvectors are available. For uniforn rank systens $z_{j}$ are conpletely free, subject only to reak honsingularity constraints on $Z$ and $t$. For non-uniforn rank systens extra freedon is available for $z{ }^{r a s s}$ asiated with loworder infinite zeros, whertas $z{ }^{1}$ for the highest order infinite zeros are often uniquely deternined.

In all three cases the radii of Butterworth patterns are a free design paraneter.

The extra degrees of freedon beyond asymptotic loop transfer recovery can be applied to satisfy secondary design objectives.

Notice that the results are derived under certain conditions. First, it is assuned that the finite zeros are distinct. Secondly, it is assured that the null-space structure of the projected Markov paraneters is sinple (i.e. diagonalizable). Further rank-constraints on certain natrices are given in $[54,56]$. However, these constraints are satisfied generically and therefore not nentioned here. For practical purposes none of these assunptions are serious linitations.

Also notice that for siso-systens the results inply a particularly sinple approach to ITR. SIso-systens are of uniforn rank, the paraweter vectors $z_{i}$ are scalars $\bar{T}$ and free to select. The left eigenvectors $w_{i}$ are then uniquely determined by $\lambda_{i}(q)$. Hence $F(q)$ is determined only by $\lambda_{i}$ (q).

Final1y notice that the requirenent of a Butterworth distribution of the fast poles is not strictly neccesary. It nerely serves as a convenient choice.

As a final renark it is possible - by duality - to state sinilar results for full state recovery of an observer loop shape (i.e. feedback design based on the output plant node).

\section{A discussion of eigenstructure-based ITR.}

In this section sone connents on the applicability of the eigenstructure-based LTR-concepts are provided. These coments nay serve as a notivation for dealing with this nethod. In particular the eigenstructure approach will be conpared to the LQG/LTR approach. The coments are to sone extent based on quantitative investigations, but sainly based on experience, since closed-form expressions for the applied measures are difficult to obtain in general. In 6 the connents made here are supported by an exanple.

Reark 1 - The eigenstructure-based LTRdesign procedure will typically be performed in 2-step nanner:

1. Target feedback design which reflects the perfornance and robustness specifications.

2. Recovery of the target design.

Fron studies in eigenstructure LTR-design it has been observed that if the fast poles $\mu$ are manipulated so that

$$
|\mu(A-F C)| \approx f \cdot|B(A-B R)|
$$

where $B$ are the doninant eigenvalues of $A-B R$ and $2<f<4$, the recovery is often achieved to within
2-3dB over the inportant band of frequencies, and better roll-off is achieved at high frequencies.

Hence it is not necessary (as often clained) to nove the eigenvalues of the observer into infinity.

Resark 2 - In order to achieve good recovery it is essential that $p$ poles of A-FC and the associated zero-directions are "close" to the zero-structure of $S(A, B, C)$. In the eigenstructure LTR-nethod this objective is achieved in a straightforward manner. In contrast in the LQG/LTR nethod this is achieved asynptotically (i.e. by decreasing the covariance of the neasurement noise). If some zeros are far away fron the associated pole of $A$ it then follows that the measurement noise nust be made very small in order to achieve good recovery. One consequence of naking the measurenent noise covariance very snall is that $F$ will becone very large, since $F \approx q B a$. This is not desirable since the individual gains of the controller are increased.

In the frequency-donain sinilar consequences apply. To see this consider the asynptotic value of $\mathrm{c}(\mathrm{s})$.

$$
C_{\text {LIHIT }}=\mathrm{K}+(\mathrm{s}) \mathrm{B} \cdot \mathrm{P}(\mathrm{s})^{-1}
$$

The maxinu singular value of a typical asynptotic $\mathrm{C}(\mathrm{s})$ is shown in figure 1 , where also typical $\sigma,[C(s)]$ curves for finite q-values are shown. Here it is seen as $q$ increases the high frequency gains of $c(s)$ are increased.

clearly it is not desirable to nake $q$ larger than actually necessary, since the ratio between noise $n(s)$ and the control signals $u(s)$ is deternined in the high frequency range by:

$$
\begin{aligned}
& u(s)=-C[I+C P]^{-1} \cdot n(s) \\
& u(s)=-C(s) \cdot n(s), \text { large }
\end{aligned}
$$

I.e. the noise is anplified into the control signals at high frequencies.

The problen of raking $q$ as suall as possible while still achieving reasonable LTR is handled directly in the eigenstructure formulation.

Concerning the fast poles of A-FC the eigenstructure nethod allows that the associated zero-directions are assigned directly (i.e. not assigned asymptotically as in the LQG/LTR approach). Again this direct assigned inproves the rate of convergence.

In performing these assignments the only remaining design paraneters are the recovery paraneter $q$ and the radii of the fast eigenvalues of A-FC. The latter paraneters are discussed next.

Renark 3. When one performs an LQG/LTR design it will usually be observed that the fast poles of A-FC are very uneven distributed - some extrenely fast and others less fast. The reason for this is that the poles approach infinity in Butterworth patterns of different orders. One consequence of making some poles much faster than the dominant poles is that the controller gains are increased. The reason for this is that $F=$ $q B \alpha$, and $\alpha$ is proportional to the radii of fast poles. To see this it can be found [54] that for non-unifor rank systems of simple structure $\alpha$ is : 


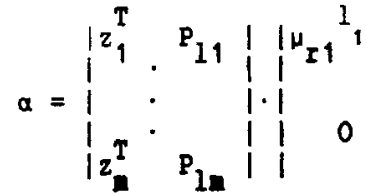

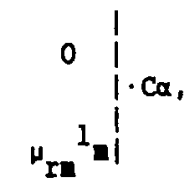

$\operatorname{rank}(C a)=$

where $\mu$ are the radii of the infinite zeros.

In order to reduce the size of the fast poles the radii can be reduced.This is easily done in the eigenstructure sethod, since the radii are manipulated directly. Actually the radii can be reduced so much that the size of all fast poles are approxinately the sane without affecting the recovery proces much. In doing so the gains of the controller are reduced (sonetines significantly), since $\alpha$ is reduced. In the LQG/LIR procedure outlined by Stein \& Athans [S2] such changes cannot be handled directly, but aust be perforned by scaling the input or output variables.

\section{Exanples.}

As the first exanple consider the following nininal systen:

$$
\begin{aligned}
& A=\left|\begin{array}{rrrr}
-30 & 10 & 34.9 & 0 \\
0 & -40 & 0 & 1 \\
0 & 0 & -35 & 0 \\
0 & 0 & 0 & -45
\end{array}\right| \quad B=\left|\begin{array}{rr}
30 & 0 \\
35 & 0 \\
-30 & 0 \\
0 & 50
\end{array}\right| \\
& C=\left|\begin{array}{rrrr}
25 & 0 & 0 & 0 \\
1 & 25 & 0 & 0
\end{array}\right|
\end{aligned}
$$

The system has a transwission zeros at $s=-0.1$, and it is of non-unifore rank but with sinple structure. The Markov paraneters are:

$$
P_{1}=\left|\begin{array}{ll}
750 & 0 \\
875 & 0
\end{array}\right| \quad P_{2}=\left|\begin{array}{rr}
-39925 & 0 \\
-35000 & 1250
\end{array}\right|
$$

According to the rules of $\$ 4$ the selection of eigenvalues and paraneter values for LTR must be in the following way:

$$
\begin{aligned}
& \lambda_{1}=-0,1, z_{1}{ }^{T} C\left(\lambda_{1}\right) B=0 \Rightarrow z_{1}= \\
& =\left[\begin{array}{ll}
-0.94837,0.31718
\end{array}\right] \\
& \lambda_{2}=\lambda r_{1} q, z_{2}{ }^{T} C B \neq 0 \Rightarrow z_{2}{ }^{T}=\left[\begin{array}{ll}
1 & 0
\end{array}\right] \\
& \lambda_{3}=\lambda_{r 2} q^{1 / 2}, z_{3}{ }^{T} \in H_{L}\left(P_{1}\right), z_{3}{ }^{T} P_{2} \neq 0 \rightarrow \\
& \lambda_{4}=\lambda_{3}=[-0.759260 .65079]
\end{aligned}
$$

From experiments with different choices of radii it turned out that for

$$
q=3 \cdot 10^{+5}, \lambda_{r 1}=-0.0012, \lambda_{r 2}=(-1+j) / / 2
$$

gave LTR to within $1 \mathrm{~dB}$ for the ninimal singular value of the sensitivity function (for sone arbitrary target design), and furthermore the radii are chosen so that all fast elgenuciues are approximately of the same size and satisfies eq. $(5-1)$ for $f \approx 4$.

This design was then compared with an LQGbased ITR design with the same target loop. The weights were selected as:

$$
\begin{aligned}
& \Gamma=\mathrm{BB}^{\mathrm{T}} \\
& \tau=\mathrm{I} \cdot \mathrm{q}
\end{aligned}
$$

as proposed in [52]. To get approxinately the same recovery as for the eigenstructure case $q$ should be selected as $q=10^{-6}$.

These two designs are now compared with respect to controller gains and recovery convergence.

If the ratio is taken between the indiviual elements of the observer-gains the following picture arises:

$$
\left|F_{\text {LOGij }} / F_{\text {ESij }}\right| \approx\left|\begin{array}{cr}
1.5 \cdot 10^{3} & 1.4 \cdot 10^{5} \mid \\
1.3 \cdot 10^{3} & 10^{3} \\
1.4 \cdot 10^{3} & 4 \cdot 10^{4} \\
2 \cdot 8 & 2 \cdot 8
\end{array}\right|
$$

indicating that the $F$ gains are several orders of agnitude larger ${ }^{\circ}$ than the $F$ gains. The reason for this is twofold. First Ehe firstorder infinite zero is very large, and secondly the second-order infinite zeros are twice as large as for the eigenstructure case. This latter effect is due to the slow convergence towards the zero at -0.1 , which forces $q$ to larger values in order to have good sensitivity recovery at DC.

If one instead looks at the $I / 0$ behaviour of $C(s)$, the singular values of $C(s)$ are shown in figure in figure 2. Again the gains of $C_{\text {ga }}$ are larger - in particular at high frequencles as expected from the discussion in 5 . The crossover of $\sigma[\mathrm{C}(\mathrm{s})]$ for the two controllers are respectively $w_{L Q G} \approx 42 \mathrm{kBz}$ and $w_{E S} \approx 18 \mathrm{kHz}$.

Finally the naxinum singular value of the sensitivity functions are shown in figure 3 . Notice that for $q=10^{-5}$ the LQG-based recovery is poor at DC. The reason for this is the slow convergence to the zero. For $q=10^{-5}$ the associated eigenvalue of $\mathrm{A}-\mathrm{FC}$ is -0.18 (almost $100 \mathrm{z}$ error), and for $q=10^{-6}$ it is -0.11 ( $10 \%$ error). This problem is easily avoided in the eigenstructure formulation.

In the second exanple the following mininal systen is considered to illustrate non-uniform rank systems of non-simple structure:

$$
\begin{aligned}
& A=\left|\begin{array}{rrrrr}
1 & 2 & -1 & 0 & 0 \\
0 & 1 & 0 & 0 & 0 \\
2 & 0 & -1 & 1 & 0 \\
1 & 0 & -1 & 1 & 2 \\
2 & 1 & 1 & -1 & 1
\end{array}\right| \\
& c=\left|\begin{array}{lllll}
1 & 0 & 0 & 0 & 0 \\
0 & 1 & 0 & 0 & 0 \\
0 & 0 & 1 & 0 & 0
\end{array}\right| \\
& B=\left|\begin{array}{lll}
1 & 0 & 0 \\
0 & 1 & 0 \\
0 & 0 & 0 \\
0 & 0 & 0 \\
0 & 0 & 1
\end{array}\right|
\end{aligned}
$$

The systen has no transaission zeros and it is non-uniform rank with non-simple structure. The syste has 2 first order infinite zeros and 1 third-order infinite zero, hence according to 4 LTR is achieved if eigenvalues and paranetervectors are selected as: 


$$
\begin{aligned}
& \lambda_{1}=\lambda_{r 1} q, z_{1}{ }^{T} \mathrm{CB} * 0 \Rightarrow z_{1}=\left[\begin{array}{lll}
1 & 0 & 0
\end{array}\right] \\
& \lambda_{2}=\lambda_{r 2} q, z_{2}{ }^{T} \mathrm{CB} * 0, z_{2}{ }^{T} \neq z_{1} \Rightarrow z_{2}= \\
& =\left[\begin{array}{lll}
0 & 1 & 0
\end{array}\right]
\end{aligned}
$$$$
\lambda_{i}=\lambda_{r i} q^{1 / 3}, \quad z_{3}^{I}=\sum_{j=0}^{1} \frac{x_{j}}{\lambda_{i}^{j}}
$$$$
\left[\begin{array}{ll}
x_{1} & x_{0}
\end{array}\right]\left[\begin{array}{ll}
\mathrm{CB} & 9 \\
\mathrm{CAB} & \mathrm{CO}
\end{array}\right]=0
$$

$\lambda_{r i} \in$ Butterworth pattern of order 3

With the radii as $[-1,(-0.5 \pm j / 3 / 2)]$ and $x_{1}=$ $\left[\begin{array}{lll}-2 & 0 & 0\end{array}\right]$ and $x_{f}=\left[\begin{array}{lll}0 & 0 & 1\end{array}\right]$. MON $z_{i}$ is

$$
z_{i}{ }^{I}=x_{0}+\frac{x_{1}}{\lambda_{r i}} q^{-1 / 3}=\left[-\frac{2}{\lambda_{r i}} q^{-1 / 3}, 0,1\right]
$$

Notice here how the vectors are functions of q. Even the first ter is vanishing it cannot be neglected. If it is neglected ITR will not be achieved - whereas the above choice ensures ITR.

\section{References}

[A1] Athans, H. - A tutorial on the IoG/LTR nethod Proc. Aerican Control conference, Seattle, $\mathrm{NR}, \mathrm{p} .1289-96,1986$.

[B1] Birdwell,J.D. \& Lanb,A.J. - Balanced singular values for IQG/LTR design, Proc. Inerican Control Conf., Seattle, WA, p.40914,1986

[D1] Doyle,J.C. \& Stein,G. - Robustness with observers, IEEE Transact Aut. Control, AC24,4, p. 607-11, 1979 .

[D2] Doyle,J.C. \& Stein,G. - Multivariable feedback design: Concepts for a classical/ nodern synthesis, IneE Transact. Aut. Control, AC-26, 1, p.4-16, 1981.

[B1] Harvey,C.A. \& Stein,G. - Quadratic weights for asymptotic regulator properties, IEEE Transact. Aut. Control, AC-23, p.37887,1978 .

[K1] Kazerooni,B. \& Boupt,P.R. - On the loop transfer recovery, Int. J. Control,43,3, p. $981-96,1986$.

[K2] Rouvaritakis,B. \& Ednunds,J.A. - multivariable root loci: $A$ unified approach to finite and infinite zeros, Int. J. Control 29, 3, P. 393-428, 1979.

[M1] Morari,M. \& Doyle,J.C. - A unifying framework for control systen design under uncertainty and its inplications for chenical proces control, 3rd Intl. Conf. on Chen. Proc. Control, Asilonar, CA, p.551,1986 .

[S1] Shaked, 0. - The asymptotic behaviour of the root-loci of nultivariable optimal regulators, IEEE Transact. Aut. Control, AC$22,4,0.597-9,9977$.

[52] Stein, G. \& Athans, $\mathbf{H}$. - The LoG/LTR procedure for aultivariable feedback control design, IEEE Iransact. Aut. Control, AC$32,2,1987$.
[53] Spgaard-Andersen, P. et.al. - A singular value sensitivity approach to robust $e i$ genstructure assignment, IEDE conf. on Decision \& Control, Athens, Greece, p.121$6,1986$.

[S4] Sugaard-indersen, P. - Issues in robust multivariable observerbased feedback design, Ph.D. thesis, Control Eng. Inst. Technical Oniversity of Denark, Lyngby, 1986.

[55] swgaard-andersen,P. - Coments on "On the loop transfer recovery", Int. J. Control, 45, 1, p. 369-74, 1987.

[56] słgaard-indersen, P. - Loop transfer recopery - an eigenstructure interpretation, subnitted for publication.

[V1] Verghese,G. Railath, T. - Coments on "On the structural invariants and the rootloci of linear nultivariable systens", Int. J. Control , 29,6, p. 1077-80, 1979.
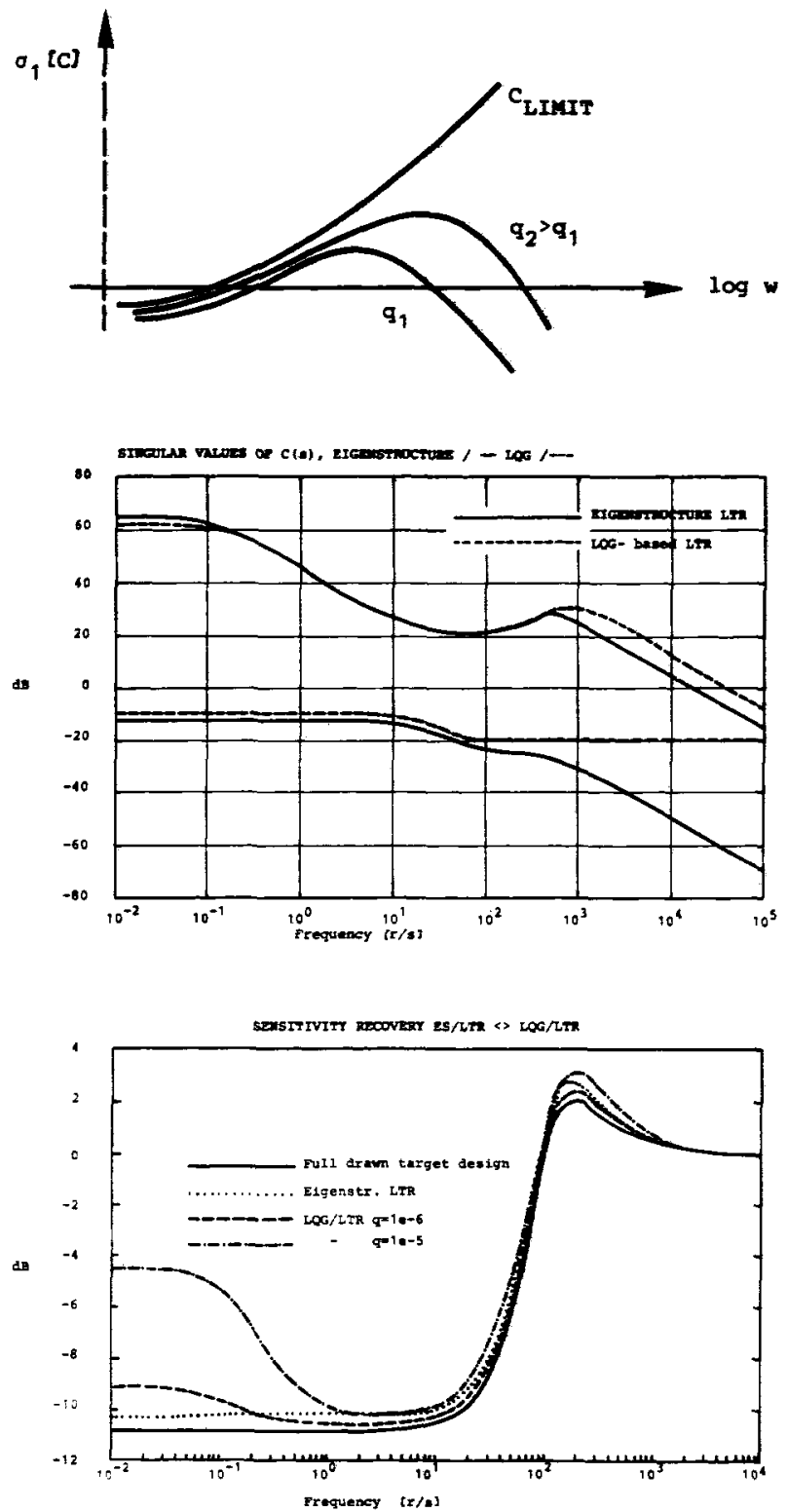